\title{
Kitasatospora cheerisanensis sp. nov., a new species of the genus Kitasatospora that produces an antifungal agent
}

\author{
Young Ryun Chung, ${ }^{1}$ Kee Cheol Sung, ${ }^{1}$ Hye Kyoung Mo, ${ }^{1}$ \\ Dae Young Son, ${ }^{2}$ Jin Sik Nam, ${ }^{3}$ Jongsik Chun ${ }^{3}$ and Kyung Sook Bae ${ }^{3}$
}

\author{
Author for correspondence: Young Ryun Chung. Tel: +82 591751 5945. Fax ; +82 5917590187. \\ e-mail: yrchung@nongae.gsnu.ac.kr
}

1,2 Department of Microbiology' and Department of Molecular Biology², Gyeongsang National University, Chinju 660-701, Republic of Korea

3 Korean Collection for Type Cultures, Korea Research Institute of Bioscience \& Biotechnology, Taejon 305-600, Republic of Korea

\begin{abstract}
An actinomycete, strain $\mathrm{YC75}^{\top}$, which produced bafilomycin-like antifungal compounds, was identified as a member of the genus Kitasatospora on the basis of morphological and chemotaxonomic characteristics. The strain produced the aerial and fragmenting vegetative mycelia consisting of straight chains of $\mathbf{2 0}$ or more smooth-surfaced spores. Submerged spores were formed in tryptic soy broth. No soluble pigments were formed. Whole-cell hydrolysates contained glucose and mannose, but not galactose. The 165 rDNA sequence of $\mathrm{YC75}^{\top}$ was compared with those of the other representative kitasatosporae and streptomycetes. Strain $\mathrm{YC75}^{\mathrm{T}}$ formed a significant monophyletic clade with Kitasatospora phosalacinea. The levels of DNA relatedness between strain $\mathrm{YC75}^{\mathrm{T}}$ and representatives of the genus Kitasatospora ranged from 16 to $59 \%$ including $K$. phosalacinea ( 28 and $40 \%$ ). It is clear from polyphasic evidence that the isolate should be classified as Kitasatospora cheerisanensis sp. nov., whose type strain is $\mathrm{YC75}^{\top}$ (= KCTC 2395'). The presence of galactose in whole-cell hydrolysates may not be a stable chemical marker for the genus Kitasatospora.
\end{abstract}

Keywords: Kitasatospora cheerisanensis sp. nov., antifungal agent, bafilomycin, actinomycete

\section{INTRODUCTION}

The genus Kitasatospora comprises a group of filamentous and aerobic Gram-positive bacteria with the aerial mycelium bearing long spore chains of more than 20 spores and is phenotypically similar to Streptomyces strains (Omura et al., 1982). Differential characteristics of the genus Kitasatospora which can be used to distinguish it from the genus Streptomyces are the higher ratio of meso-diaminopimelic acid (DAP) to LL-DAP and the presence of galactose in the whole-cell hydrolysates (Omura et al., 1982; Zhang et al., 1997). Wellington et al. (1992) proposed to unify two taxa on the basis of rRNA-targeted oligonucleotide probes and phenotypic properties. This proposal was later supported by ribosomal protein AT-L30 analysis (Ochi

\footnotetext{
Abbreviations: DAP, diaminopimelic acid; ISP, International Streptomyces Project.

The GenBank accession number for the $16 \mathrm{~S}$ rDNA sequence of strain $\mathrm{YC75}^{\mathrm{T}}$ is AF050493.
}

\& Hiranuma, 1994). In a recent phylogenetic study based on complete $16 \mathrm{~S}$ rDNA sequence data, Zhang et al. (1997), however, proposed to revive the genus Kitasatospora as they form a significant monophyletic clade and contain differential chemotaxonomic markers, notably relatively larger amount of mesoDAP and galactose in their cell walls. Kitasatospora species, like streptomycetes, have been known to produce several antifungal and antibacterial agents (Kusakabe \& Kiyoshi, 1988; Nakamura et al., 1989). Several antifungal agents, such as validamycin and polyoxin produced by Streptomyces species, were developed and now are commercially available for agricultural fungicides (Yamaguchi, 1995).

An actinomycete strain, designated $\mathrm{YC75}$, was isolated from a soil humus sample collected from Cheerisan, a mountain in the Republic of Korea, in the process of screening biological control agents for the plantpathogenic fungus Rhizoctonia solani (Sung \& Chung, 1997). The strain produced an antifungal agent which inhibits mycelial growth of several important plant 
pathogens, namely Botrytis cinerea, Colletotrichum lagenarium, Rhizoctonia solani and Sclerotinia sclerotiorum. The taxonomic status of strain $\mathrm{YC}^{\mathrm{T}} \mathrm{5}^{\mathrm{T}}$ was investigated using a combination of phenotypic, chemical and molecular systematic means. On the basis of polyphasic evidence, we propose strain $\mathrm{YC}^{\mathrm{T}}$ be classified as Kitasatospora cheerisanensis sp. nov.

\section{METHODS}

Bacterial strain. Strain $\mathrm{YC75}^{\mathrm{T}}$ was isolated from a soil humus sample collected at Cheerisan mountain, Republic of Korea, using standard dilution agar plate methods. Aliquots of serially diluted soil suspension were inoculated onto trypticase soy agar (TSA; BBL) plates, followed by incubation at $28^{\circ} \mathrm{C}$ for $3 \mathrm{~d}$. Bacterial colonies were picked up and their inhibitory activities against $R$. solani were determined by paired bioassay on TSA plates. An isolate, designated $\mathrm{YC}^{\mathrm{T}} 5^{\mathrm{T}}$, showed substantial inhibition on mycelial growth of the fungus and was studied further. The reference strains were obtained from Korean Collection for Type Cultures (KCTC), Korea Research Institute of Bioscience and Biotechnology, Taejeon, Korea. The test strains were maintained on $\mathrm{YM}$ agar $\left(1^{-1}: 3 \mathrm{~g}\right.$ yeast extract, $3 \mathrm{~g}$ malt extract, $5 \mathrm{~g}$ peptone, $10 \mathrm{~g}$ dextrose, $20 \mathrm{~g}$ agar) or Bennett's agar $\left(1^{-1}: 1 \mathrm{~g}\right.$ yeast extract, $1 \mathrm{~g}$ beef extract, $2 \mathrm{~g} \mathrm{~N}-\mathrm{Z}$ amine type A, $10 \mathrm{~g}$ glucose, $20 \mathrm{~g}$ agar).

Cultural and morphological characteristics. Cultural properties were examined by 14-d-old cultures grown on the media recommended by the International Streptomyces Project (ISP) (Shirling \& Gottlieb, 1966). Morphological characteristics were examined using light microscopy and scanning electron microscopy (JEOL model JSM-6400).

Chemotaxonomy. Analyses of diaminopimelic acid and sugars were carried out according to Lechevalier \& Lechevalier (1970). The biomass for cellular fatty acid analysis was prepared from one d-old culture grown on TSA plate at $28^{\circ} \mathrm{C}$. Fatty acid methyl esters were prepared using the method described in the manual of Hewlett Packard Microbial Identification System (MIDI). The resultant esters were separated using a gas chromatograph (model 5890; Hewlett Packard) fitted with a methyl phenyl silicon fused silica capillary column ( $25 \mathrm{~m}$ by $0.2 \mathrm{~mm}$; Hewlett Packard). Phospholipids were extracted from freeze-dried cells with chloroform/methanol $/ 0.3 \%$ aqueous sodium chloride ( $9: 10: 3$, by vol.) and detected by two-dimensional TLC according to Embley \& Wait (1994). Isoprenoid quinones were analysed by using mass spectrometry (Collins, 1994).

Physiological tests. Catalase activity, acid production from carbohydrates, utilization of carbohydrates as the sole carbon source for growth, hydrolysis and decomposition of casein, cellulose, starch, chitin, aesculin, gelatin, hippurate, hypoxanthine, tyrosine and Tween 40 were performed by the methods described by Smibert \& Krieg (1981). Growth in the presence of sodium chloride $(1,3$ and $5 \%, w / v)$ and sensitivity to antibiotics were determined on nutrient agar at $28^{\circ} \mathrm{C}$. The temperature and $\mathrm{pH}$ ranges for growth were tested on nutrient agar.

DNA-DNA hybridization. Chromosomal DNA was prepared following the method of Marmur (1961). The levels of DNA relatedness between test strains were measured using the procedure of Sambrook et al. (1989). Duplicate aliquots containing $200 \mathrm{ng}$ of each denatured genomic DNA were transferred onto positively charged nylon membranes (Hybond-N + ; Amersham) by using dot blot apparatus (Bio-Rad). The membranes were air-dried and cross-linked in a UV illuminator for $1 \mathrm{~min}$. Twenty-five nanograms of DNA were denatured by boiling for $5 \mathrm{~min}$, labelled using rediprime DNA-labelling system (Amersham) with Redivue $\left[{ }^{32} \mathrm{P}\right] \mathrm{dCTP}$ (Amersham), and purified by using NucTrap Probe Purification Columns (Stratagene). The membranes were prehybridized in hybridization solution $(5 \times$ Denhardt's reagent, $6 \times$ SSC, $0.5 \%$ SDS, $100 \mu \mathrm{g}$ denatured fragmented salmon sperm DNA ml ${ }^{-1}$, and $35 \%$ formamide) at $65^{\circ} \mathrm{C}$ for $1 \mathrm{~h}$. The labelled probe DNAs were then added to the hybridization solutions and incubated at $65^{\circ} \mathrm{C}$ for $18 \mathrm{~h}$. The resultant membranes were washed at $65^{\circ} \mathrm{C}$ for 5 min with $2 \times$ SSC and $0.1 \%$ SDS. After $24 \mathrm{~h}$ exposure of the membrane at $-70^{\circ} \mathrm{C}$, the signal intensities were measured using a densitometer (Bio-Rad) and peak-areas determined by 1-D Analyst II software (Bio-Rad). The signal produced by self-hybridization of the probe with homologous target DNA was taken as $100 \%$ and the percentage homology values calculated for the duplicated slots.

DNA base composition. The $\mathrm{G}+\mathrm{C}$ content of the DNA was determined from the midpoint value of the thermal denaturation profile using a spectrophotometer (Ultrospec 2000; Pharmacia Biotech) equipped with a programmable peltier temperature-control unit by the equation of Marmur \& Doty (1962), as modified by De Ley (1970).

16S rDNA sequencing. The 16S rDNA was enzymically amplified using two oligonucleotide primers based on published sequences (Collins et al., 1994). The sequences of the two primers are $5^{\prime}$ TATGGATCCTTCTACGGAGAGTTTGATCC $3^{\prime}$ and 5' TATGGATCCCACCTTCCGGTACGGCTACC $3^{\prime}$ (BamHI sites are in bold). The temperatures for denaturation, annealing and extension were 92,55 and $72{ }^{\circ} \mathrm{C}$, respectively. The PCR products were digested with BamHI and cloned into the same site of the pBluescript II SK $(+)$ vector. Overlapping subclones were generated by exonuclease III digestion of the insert DNA. The nucleotide sequences of these clones were determined using the Sequenase version $2.0 \mathrm{kit}$ (USB). The resultant $16 \mathrm{~S}$ rDNA sequence of strain $\mathrm{YC}^{\mathrm{T}}$ was manually aligned with representative sequences (positions 32-71, 98-1135, 11401450 and 1454-1507 of $E$. coli numbering) of actinomycetes obtained from the Ribosomal Database Project (Maidak et al., 1997) and GenBank databases. Phylogenetic trees were inferred by using four treeing algorithms, namely the Fitch-Margoliash (Fitch \& Margoliash, 1967), maximumlikelihood (Felsenstein, 1981), maximum-parsimony (Fitch, 1972) and neighbour-joining (Saitou \& Nei, 1987) methods. Evolutionary distance matrices for the neighbour-joining and Fitch-Margoliash methods were generated according to Jukes \& Cantor (1969). The PHYLIP package (Felsenstein, 1993) was used for all analyses. The resultant unrooted tree topology was evaluated in bootstrap analyses (Felsenstein, 1985) of the neighbour-joining method based on 1000 resamplings.

\section{RESULTS}

\section{Morphological characteristics}

Strain $\mathrm{YC}^{\mathrm{T}}$ produced the aerial mycelium which consisted of straight chains of 20 or more rod-shaped smooth-surfaced spores $(0.75-0.90$ by $1.2-1.5 \mu \mathrm{m})$ 


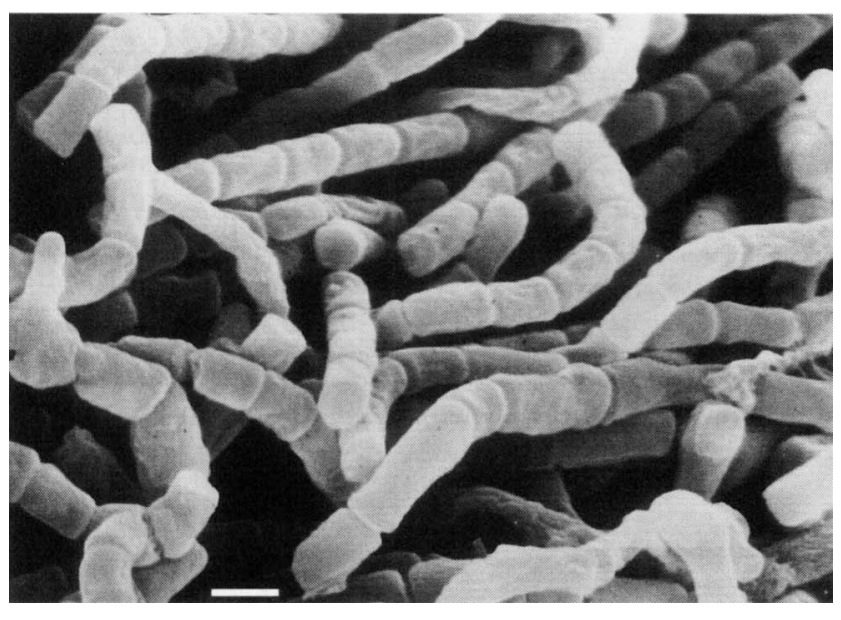

Fig. 1. Scanning electron micrograph showing the smooth surfaces of spores of strain YC75 $\left(=K C T C 2395^{\top}\right)$. The organism was grown on potato dextrose agar at $28{ }^{\circ} \mathrm{C}$ for $14 \mathrm{~d}$. Bar, $1 \mu \mathrm{m}$.

(Fig. 1). The vegetative mycelia grown in TSA or trypticase soy broth (TSB) were easily fragmented and submerged spores were formed in TSB. The isolate grew well on various organic media and produced abundant aerial spores on inorganic salt-starch agar (ISP medium 4), tyrosine agar (ISP medium 7), potatodextrose agar and Bennett's agar plates (Table 1). The spore mass was whitish-grey and the reverse sides of colonies were greenish-yellow on most agar media. No soluble pigments were produced. Colonies lacking aerial mycelium during early growth stage were pasty, circular, convex and dull milky on $0 \cdot 1 \times$ TSA plate.

\section{Chemotaxonomy}

Strain $\mathrm{YC}^{\mathrm{T}} 5^{\mathrm{T}}$ contained meso-DAP and LL-DAP in the whole-cell hydrolysate. No galactose was detected, but glucose and mannose were present in the wholecell hydrolysate. Phosphatidylethanolamine, phosphatidylinositol, diphosphatidyl glycerol and six unidentified phospholipids were contained in the polar lipid fraction. The predominant fatty acids in wholecell methanolysates were $15: 0$ iso $(35.4 \%), 15: 0$ anteiso $(18.3 \%), 16: 0(10 \cdot 9 \%)$ and $17: 0$ iso $(8 \cdot 3 \%)$. The major menaquinone type was MK- $9\left(\mathrm{H}_{8}\right)$. The $\mathrm{G}+\mathrm{C}$ content of the DNA was $75.8 \mathrm{~mol} \%$.

\section{Physiological characteristics}

Following characteristics of strain $\mathrm{YC}^{\mathrm{T}} 5^{\mathrm{T}}$ were positive: catalase activity, reduction of nitrate, production of acid from arabinose, cellobiose, galactose, glucose, maltose, trehalose and xylose. Casein, chitin, chitosan, starch, aesculin, gelatin, hippurate and Tweens 40, 60 and 80 were decomposed, but cellulose, hypoxanthine and tyrosine were not decomposed. Growth occurred in the presence of $1 \%$, but not in $3 \%$ sodium chloride. The growth also occurred at $\mathrm{pH} 4-9$ and the temperature range of $20-37^{\circ} \mathrm{C}$. Strain $\mathrm{YC}^{\mathrm{T}} 5^{\mathrm{T}}$ utilized arabinose, azelate, cellobiose, cronate, fumarate, Dglucose, galactose, iso-butyrate, malonate, maltose, rhamnose, trehalose and xylose for growth, but not adonitol, fructose, glycerol, mannitol, myo-inositol, melezitose, raffinose, sorbitol, suberate, succinate or sucrose. This strain was susceptible to ampicillin, chloramphenicol, kanamycin, nalidixic acid, oxytetracycline, rifampicin and streptomycin.

The strain $\mathrm{YC}^{\mathrm{T}} 5^{\mathrm{T}}$ inhibited mycelial growth of several plant-pathogenic fungi, such as $R$. solani, Botrytis cinerea, Sclerotinia sclerotiorum, Pythium ultimum, Colletotrichum lagenarium, Magnaporthe grisea and Botryosphaeria dothidea by producing bafilomycin-C1like antifungal compounds (personal communications with Dr S. S. Moon, Kongju National University, Korea).

\section{Molecular systematics}

An almost complete 16S rDNA sequence was determined for strain $\mathrm{YC}^{\mathrm{T}}$ (1514 nucleotides). The preliminary phylogenetic analysis based on a large

\section{Table 1. Morphological characteristics of strain $Y C 75^{\top}$}

All characteristics were observed after 2 weeks incubation at $28^{\circ} \mathrm{C}$. On all media: growth was good; where present, spore mass colour was whitish-grey; and soluble pigment was absent.

\begin{tabular}{|c|c|c|}
\hline Medium & Sporulation & Reverse colour \\
\hline Yeast extract/malt extract agar (ISP No. 2) & Moderate & Greenish-yellow \\
\hline Oatmeal agar (ISP no. 3 ) & Moderate & Greyish-white \\
\hline Inorganic salt-starch agar (ISP No. 4) & Abundant & Greyish-white \\
\hline Glycerol-asparagine agar (ISP No. 5) & Poor & Grey \\
\hline Peptone/yeast extract iron agar (ISP No. 6) & None & Greenish-yellow \\
\hline Tyrosine agar (ISP no. 7) & Abundant & Greenish-yellow \\
\hline Potato dextrose agar & Abundant & Deep yellow \\
\hline Tryptic soy agar & None & Greenish-yellow \\
\hline Nutrient agar & None & Greenish-yellow \\
\hline Bennett's agar & Abundant & Greenish-yellow \\
\hline Starch agar & Moderate & Greenish-yellow \\
\hline
\end{tabular}




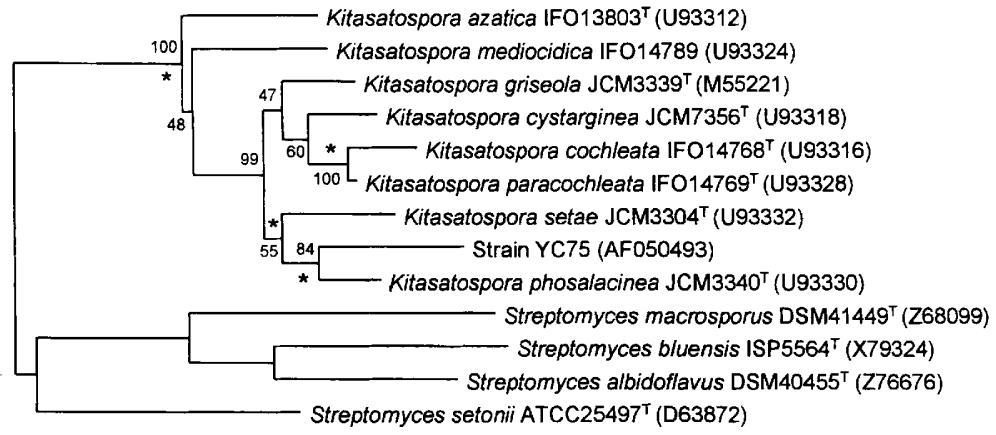

0.01
Fig. 2. Unrooted neighbour-joining tree based on 1445 unambiguously aligned nucleotide positions including positions $32-71,98-1135,1140-1450$ and 1454-1507 of $E$. coli numbering. Asterisks indicate the branches that were also recovered in the remaining three methods employed in this study (see text for details). The numbers at the nodes exhibit the levels of bootstrap support based on neighbour-joining analyses of 1000 resampled data sets. The corresponding accession numbers are given in parentheses. Bar represents 0.01 nucleotide substitution per position.

Table 2. DNA relatedness of strain $\mathrm{YC75}^{\top}$ to representatives of the genus Kitasatospora species

\begin{tabular}{|lcccc|}
\hline \multirow{2}{*}{ Strain } & \multicolumn{4}{c|}{ Labelled DNAs } \\
\cline { 2 - 5 } & YC75 $^{\mathbf{T}}$ & KCTC 9746 $^{\mathbf{T}}$ & KCTC 9745 $^{\mathbf{T}}$ & KCTC 9735 $^{\mathbf{T}}$ \\
\hline Strain YC75 & 100 & 26 & 46 & 28 \\
K. cystarginea KCTC 9746 $^{\mathrm{T}}$ & 16 & 100 & 12 & 19 \\
K. griseola KCTC 9745 & 59 & 36 & 100 & 28 \\
K. mediocidica KCTC 9733 & 18 & 19 & 23 & 9 \\
K. phosalacinea KCTC 9735 & 40 & 33 & 61 & 100 \\
K. setae KCTC 9182 & 42 & 35 & 59 & 42 \\
\hline
\end{tabular}

data set consistently placed strain $\mathrm{YC}^{\mathrm{T}} 5^{\mathrm{T}}$ in a clade corresponding to the genus Kitasatospora (data not shown). When the phylogenetic position of isolate YC75 ${ }^{\mathrm{T}}$ was investigated with all of validly described species of the genus Kitasatospora and representatives of the genus Streptomyces, the organism formed a monophyletic clade with the type strain of Kitasatospora phosalacinea (Fig. 2). The relationship was evident in evolutionary trees based on four different treeing methods and also supported by a high bootstrap value of $84 \%$. Nucleotide sequence similarity values between the isolate and kitasatosporae range from $97.0 \%$ (Kitasatospora azatica) to $98.5 \%$ (K. phosalacinea). Kitasatospora phosalacinea and Kitasatospora griseola $(98.1 \%)$ were the only species that represent more than $98 \%$ sequence similariy. The genealogical position of isolate $\mathrm{YC}^{\mathrm{T}}$ was further examined using DNA-DNA pairing study. DNA relatedness values between our isolate and representatives of the genus Kitasatospora ranged from $16 \%$ (with Kitasatospora cystarginea) to $59 \%$ ( $K$. griseola) (Table 2).

\section{DISCUSSION}

It is clear from phylogenetic analyses based on $16 \mathrm{~S}$ rDNA sequences that strain $\mathrm{YC}^{\mathrm{T}} 5^{\mathrm{T}}$ belongs to the genus Kitasatospora. In a comparison of some phenotypic characteristics of strain YC75 ${ }^{\mathrm{T}}$ with those of phylogenetically related Kitasatospora species,
Kitasatospora azatica, Kitasatospora cochleata, K. cystarginea, K. griseola, Kitasatospora mediocidica, Kitasatospora setae, Kitasatospora paracochleata and $K$. phosalacinea, strain $\mathrm{YC}^{\mathrm{T}} \mathrm{T}$ had unique differential properties as shown in Table 3 (Labeda, 1988; Nakagaito et al., 1992; Nakamura et al., 1989). Only strain $\mathrm{YC}^{\mathrm{T}}$ liquified gelatin and produced bafilomycin-C1-like antifungal agents. Many Kitasatospora species were known to produce antifungal and antibacterial agents such as cystargin and setamycin (Kusakabe \& Kiyoshi, 1988; Omura et al., 1989). Rhamnose is utilized only by strain $\mathrm{YC} 75^{\mathrm{T}}$ and $K$. phosalacinea, which is most closely related to the strain $\mathrm{YC75}^{\mathrm{T}}$ in the phylogenetic analysis. The presence of galactose in the whole-cell hydrolysate, which distinguishes the genus Kitasatospora from the genus Streptomyces, was not confirmed even by the analysis using HPLC in our study (Omura et al., 1982; Zhang et al., 1997). Instead the strain $\mathrm{YC}^{\mathrm{T}}$ was found to contain glucose and mannose in the whole-cell hydrolysate. This suggests that the presence of galactose may not be a good criterion for recognizing the genus Kitasatospora, as our isolate was clearly assigned to the genus based on 16S rDNA analysis. As shown in Fig. $2,16 \mathrm{~S}$ rDNA analysis showed not only that strain $\mathrm{YC}^{\mathrm{T}}$ is an authentic member of the genus Kitasatospora but also that the closest phylogenetic neighbour is $K$. phosalacinea. DNA relatedness values lower than $59 \%$ with five Kitasatospora species including $K$. phosalacinea further indicate that the organism is 
Table 3. Morphological, physiological and biochemical characteristics of strain $\mathrm{YC75}^{\top}$ and phylogenetically related Kitasatospora species

+ , Positive; -, negative; v, variable.

\begin{tabular}{|c|c|c|c|c|c|c|c|c|c|}
\hline Character & Strain $Y_{C} 75^{\mathrm{T}}$ & K. azatica ${ }^{*}$ & K. cochleata ${ }^{\star}$ & K. cystarginea ${ }^{\star}$ & K. griseola $\dagger$ & K. mediocidica ${ }_{+}^{+}$ & K. setae ${ }^{*}$ & $K$. paracochleat ${ }^{*}$ & $K$. phosalacinea ${ }^{\star}$ \\
\hline Aerial mycelia & Rectiflexibiles & Rectiflexibiles & Hook to spirales & Spirales & & Rectiflexibiles & Rectiflexibiles & Spirales & Rectiflexibiles \\
\hline Soluble pigment & - & - & Yellowish-brown & - & Pink & Brown & - & Yellowish-brown & - \\
\hline Melanin formation & - & - & + & - & - & - & - & + & - \\
\hline Nitrate reduction & + & + & - & - & - & - & + & + & + \\
\hline Starch hydrolysis & + & + & + & + & + & + & + & + & + \\
\hline Gelatin liquefaction & + & - & - & - & - & - & - & - & - \\
\hline Antibiotic produced $\dagger$ & Bafilomycin & Azaamino acid & & Cystargin & Setamycin & Mediocidin & Setamycin & & Phosalacine \\
\hline \multicolumn{10}{|c|}{ Utilization of carbohydrates: } \\
\hline L-Arabinose & + & + & + & - & + & + & + & - & - \\
\hline D-Fructose & - & + & - & - & - & + & - & + & + \\
\hline D-Glucose & + & + & + & + & + & + & + & + & + \\
\hline Inositol & - & - & - & - & - & - & - & - & - \\
\hline D-Mannitol & - & - & - & - & - & $\mathrm{v}$ & - & - & - \\
\hline Raffinose & - & - & - & - & + & - & - & - & - \\
\hline L-Rhamnose & + & - & - & - & - & - & - & - & + \\
\hline Sucrose & - & - & - & - & - & + & - & - & - \\
\hline D-Xylose & + & + & - & - & + & + & + & - & + \\
\hline Galactose in whole cells & - & + & + & + & + & + & + & + & + \\
\hline $\mathrm{G}+\mathrm{C}$ content $(\mathrm{mol} \%)$ & $75 \cdot 8$ & $70 \cdot 5$ & $72 \cdot 4$ & $70 \cdot 6$ & $66 \cdot 0$ & $74-0$ & $73 \cdot 2$ & $73 \cdot 1$ & $73 \cdot 3$ \\
\hline
\end{tabular}

* Data from Nakagaito et al. (1992).

† Data from Nakamura et al. (1989).

†Data from Labeda (1988).

genetically distinctive and forms a genomic species in the genus Kitasatospora, which satisfies the critical value proposed by Wayne et al. (1987). We therefore propose the new name Kitasatospora cheerisanensis for strain $\mathrm{YC}^{\mathrm{T}} 5^{\mathrm{T}}$ on the basis of the phenotypic, chemical and molecular systematic data.

\section{Description of Kitasatospora cheerisanensis sp. nov.}

Kitasatospora cheerisanensis (chee.ri.sanen'sis. M.L. masc. adj. cheerisanensis pertaining to Cheerisan, the name of a mountain in Korea where the species was originated).

Aerobic, Gram-positive, non-acid-fast actinomycete which produces a greenish-yellow substrate mycelium and a whitish-grey aerial mycelium on yeast extractmalt extract agar, inorganic salt-starch agar, tyrosine agar, Bennett's agar and starch agar. Vegetative mycelia fragment into bacillary structures. Spore chains are rectiflexibiles, with 20 or more rod-shaped smooth-surfaced spores $(0.75-0.90$ by $1.2-1.5 \mu \mathrm{m})$ per chain. Submerged spores are formed in liquid culture. Soluble pigments including melanin are not produced. Colonies lacking aerial mycelium during early growth stage were pasty, circular, convex and dull milky on $0 \cdot 1 \times$ TSA. The cell wall contains meso-DAP and LLDAP. Whole-cell hydrolysates contain glucose and mannose, but lack galactose. Phosphatidylethanolamine, phosphatidylinositol, diphosphatidylglycerol are contained in the polar lipid fraction. The predominant fatty acids are saturated iso- and anteisobranched as well as straight-chain fatty acids. The major menaquinone type is $\mathrm{MK}-9\left(\mathrm{H}_{8}\right)$. The strain is positive for catalase activity and reduction of nitrate.
Acids are produced from arabinose, cellobiose, galactose, glucose, maltose, trehalose and xylose. Casein, chitin, chitosan, starch, aesculin, gelatin, hippurate and Tweens 40, 60 and 80 are decomposed, but cellulose, hypoxanthine and tyrosine are not. Growth occurs in the presence of $1 \% \mathrm{NaCl}$, but not in $3 \%$

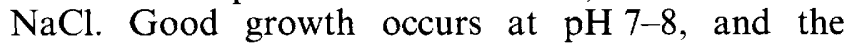
optimum temperature range is $25-30^{\circ} \mathrm{C}$. Arabinose, azelate, cellobiose, cronate, fumarate, D-glucose, galactose, iso-butyrate, malonate, maltose, rhamnose, trehalose and xylose are utilized for growth, but adonitol, fructose, glycerol, mannitol, myo-inositol, melezitose, raffinose, sorbitol, suberate, succinate and sucrose are not utilized. This strain is susceptible to ampicillin, chloramphenicol, kanamycin, nalidixic acid, oxytetracycline, rifampicin and streptomycin. The type strain $\mathrm{YC}^{\mathrm{T}} 5^{\mathrm{T}}$ produced bafilomycin-Cl-like antifungal compounds. The $\mathrm{G}+\mathrm{C}$ content of the DNA is $75.8 \mathrm{~mol} \%$. The type strain is Kitasatospora cheerisanensis YC75 ${ }^{\mathrm{T}}$ and has been deposited in Korean Collection for Type Cultures as KCTC $2395^{\mathrm{T}}$.

\section{ACKNOWLEDGEMENTS}

This work was supported by a grant no. KOSEF 96-04-0201-01-3 from the Korea Science and Engineering Foundation (KOSEF). We thank Dr D. B. Lim at Department of Microbiology, Gyeongsang National University for the comments and suggestions.

\section{REFERENCES}

Collins, M. D. (1994). Isoprenoid quinones. In Chemical Methods in Prokaryotic Systematics, pp. 265-309. Edited by $\mathbf{M}$. Goodfellow \& A. G. O'Donnell. Chichester: Wiley. 
Collins, M. D., Cockcroft, S. \& Wallbanks, S. (1994). Phylogenetic analysis of a new LL-diaminopimelic acid-containing coryneform bacterium from herbage, Nocardioides plantarum sp. nov. Int J Syst Bacteriol 44, 523-526.

De Ley, J. (1970). Re-examination of the association between melting point, buoyant density, and chemical base composition of deoxyribonucleic acid. J Bacteriol 101, 738-754.

Embley, T. M. \& Wait, R. (1994). Structural lipids of eubacteria. In Chemical Methods in Prokaryotic Systematics, pp. 121-161. Edited by M. Goodfellow \& A. G. O'Donnell. Chichester: Wiley.

Felsenstein, J. (1981). Evolutionary trees from DNA sequences: a maximum likelihood approach. $J$ Mol Evol 17, 368-376.

Felsenstein, J. (1985). Confidence limits on phylogenies: an approach using the bootstrap. Evolution 39, 783-791.

Felsenstein, J. (1993). PHYLIP (Phylogeny Inference Package) version $3.5 \mathrm{c}$. Seattle: University of Washington.

Fitch, W. M. (1972). Toward defining the course of evolution: minimum change for a specific tree topology. Syst Zool 20, 406-416.

Fitch, W. M. \& Margoliash, E. (1967). Construction of phylogenetic trees. Science 155, 279-284.

Jukes, T. H. \& Cantor, C. R. (1969). Evolution of protein molecules. In Mammalian Protein Metabolism, vol. 3, pp. 21-132. Edited by H. N. Munro. New York: Academic Press.

Kusakabe, H. \& Kiyoshi, I. (1988). Taxonomic studies on Kitasatosporia cystarginea sp. nov., which produces a new antifungal antibiotic cystargin. $J$ Antibiot (Tokyo) 41, $1758-1762$.

Labeda, D. (1988). Kitasatosporia mediocidica sp. nov. Int J Syst Bacteriol 38, 287-290.

Lechevalier, M. P. \& Lechevalier, H. A. (1970). Chemical composition as a criterion in the classification of aerobic actinomycetes. Int J Syst Bacteriol 20, 435-443.

Maidak, B. L., Olsen, G. J., Larsen, N., Overbeek, R., McCaughey, M. J. \& Woese, C. R. (1997). The RDP (Ribosomal Database Project). Nucleic Acids Res 25, 109-111.

Marmur, J. (1961). A procedure for the isolation of deoxyribonucleic acid from microorganisms. $J$ Mol Biol 3, 208-218.

Marmur, J. \& Doty, P. (1962). Determination of the base composition of deoxyribonucleic acid from its thermal denaturation temperature. $J$ Mol Biol 5, 109-118.

Nakagaito, Y., Yokota, A. \& Hasegawa, T. (1992). Three new species of the genus Streptomyces: Streptomyces cochleatus sp. nov., Streptomyces paracochleatus sp. nov., and Streptomyces azaticus sp. nov. J Gen Appl Microbiol 38, 105-120.

Nakamura, Y., Ono, E., Kohda, T. \& Shibai, H. (1989). Two new carbapenem antibiotic-producing actinomycetes: Kitasatosporia papulosa sp. nov. and Kitasatosporia grisea sp. nov. $J$ Antibiot (Tokyo) 42, 18-29.

Ochi, K. \& Hiranuma, H. (1994). A taxonomic review of the genera Kitasatosporia and Streptoverticillium by analysis of ribosomal protein AT-L30. Int J Syst Bacteriol 44, 285-292.

Omura, S., Takahashi, Y., Iwai, Y. \& Tanaka, H. (1982). Kitasatosporia, a new genus of the order Actinomycetales. $J$ Antibiot (Tokyo) 35, 1013-1019.

Omura, S., Takahashi, Y. \& Iwai, Y. (1989). Genus Kitasatosporia Omura, Takahashi, Iwai and Tanaka 1983a, 672 ${ }^{\text {vp }}$. In Bergey's Manual of Systematic Bacteriology, vol. 4, pp. 2494-2598. Edited by S. T. Williams, M. E. Sharpe \& J. G. Holt. Baltimore: Williams \& Wilkins.

Saitou, N. \& Nei, M. (1987). The neighbor-joining method: a new method for reconstructing phylogenetic trees. Mol Biol Evol 4 , 406-425.

Sambrook, J., Fritsch, E. F. \& Maniatis, T. (1989). Molecular Cloning: a Laboratory Manual, 2nd edn. Cold Spring Harbor, NY: Cold Spring Harbor Laboratory.

Shirling, E. B. \& Gottlieb, D. (1966). Methods for characterization of Streptomyces species. Int J Syst Bacteriol 16, 313-340.

Smibert, R. M. \& Krieg, N. R. (1981). General characterization. In Manual of Methods for General Bacteriology, pp. 409-433. Edited by P. Gerhardt, R. G. E. Murray, R. N. Costilow, E. W. Nester, W. A. Wood, N. R. Krieg \& G. B. Phillips. Washington, DC: American Society for Microbiology.

Sung, K. C. \& Chung, Y. R. (1997). Enhanced suppression of rice sheath blight using combination of bacteria which produce chitinases or antibiotics. In Plant Growth-Promoting Rhizobacteria: Present Status and Future Prospects, pp. 370-372. Edited by A. Ogoshi, K. Kobayashi, Y. Homma, F. Kodama, N. Kondo \& S. Akino. Paris: OECD Press.

Wayne, L. G., Brenner, D. J., Colwell, R. R. \& 9 other authors (1987). International Committee on Systematic Bacteriology. Report of the ad hoc committee on reconciliation of approaches to bacterial systematics. Int J Syst Bacteriol 37, 463-464.

Wellington, E. M., Stackebrandt, E., Sanders, D., Wolstrup, J. \& Jorgensen, N. O. (1992). Taxonomic status of Kitasatosporia, and proposed unification with Streptomyces on the basis of phenotypic and 16S rRNA analysis and emendation of Streptomyces Waksman and Henrici 1943, 339 ${ }^{\mathrm{AL}}$. Int J Syst Bacteriol 42, 156-160.

Yamaguchi, I. (1995). Antibiotics as antifungal agents. In Modern Selective Fungicides, pp. 415-429. Edited by H. Lyr. Villengang: Gustav Fischer Verlag.

Zhang, Z., Wang, Y. \& Ruan, J. (1997). A proposal to revive the genus Kitasatospora (Omura, Takahashi, Iwai, and Tanaka 1982). Int J Syst Bacteriol 47, 1048-1054. 